\title{
Gene Therapy for X-Linked Severe Combined Immunodeficiency: Where Do We Stand?
}

\author{
Marina Cavazzana, ${ }^{1-4, *}$ Emmanuelle Six, ${ }^{2-4}$ Chantal Lagresle-Peyrou, ${ }^{2-4}$ \\ Isabelle André-Schmutz, ${ }^{2-4}$ and Salima Hacein-Bey-Abina ${ }^{1,2,5,6, *}$ \\ ${ }^{1}$ Biotherapy Department, Necker Children's Hospital, Assistance Publique-Hôpitaux de Paris, Paris, ${ }^{2}$ Biotherapy Clinical Investigation Center, Groupe Hospitalier \\ Universitaire Ouest, Assistance Publique-Hôpitaux de Paris, INSERM, Paris, ${ }^{3}$ Paris Descartes-Sorbonne Paris Cité University, Imagine Institute, Paris, ${ }^{4}$ INSERM UMR \\ 1163, Laboratory of Human Lymphohematopoiesis, Paris, ${ }^{5}$ UTCBS CNRS 8258-INSERM U1022, Faculté des Sciences Pharmaceutiques et Biologiques, Université \\ Paris Descartes, Paris, and ${ }^{6}$ Immunology Laboratory, Groupe Hospitalier Universitaire Paris-Sud, AP-HP, Le-Kremlin-Bicêtre, France.
}

More than 20 years ago, X-linked severe combined immunodeficiency (SCID-X1) appeared to be the best condition to test the feasibility of hematopoietic stem cell gene therapy. The seminal SCID-X1 clinical studies, based on first-generation gammaretroviral vectors, demonstrated good long-term immune reconstitution in most treated patients despite the occurrence of vector-related leukemia in a few of them. This gene therapy has successfully enabled correction of the T cell defect. Natural killer and B cell defects were only partially restored, most likely due to the absence of a conditioning regimen. The success of these pioneering trials paved the way for the extension of gene-based treatment to many other diseases of the hematopoietic system, but the unfortunate serious adverse events led to extensive investigations to define the retrovirus integration profiles. This review puts into perspective the clinical experience of gene therapy for SCID-X1, with the development and implementation of new generations of safer vectors such as selfinactivating gammaretroviral or lentiviral vectors as well as major advances in integrome knowledge.

\section{INTRODUCTION}

GENE THERAPY has proven to be a powerful strategy for the complementation of several monogenic, inherited diseases of the hematopoietic system. The several "back and forth" steps between the bench and the bedside over the last 20 years-emphasizing the complexity of this molecular medicine-have shown how important it is to integrate knowledge from a variety of complex fields when seeking to enhance therapeutic efficacy and reduce potential side effects. Here, we review the biological and medical history of this field, describe the main achievements to date, and summarize the remaining challenges in terms of safety, long-term reconstitution, and applications outside the field of severe combined immunodeficiency (SCID).

\section{THE PATHOPHYSIOLOGY OF X-LINKED SCID}

X-linked severe combined immunodeficiency (SCID-X1) is caused by mutations of the $\gamma_{\mathrm{c}}$-encoding gene and accounts for $30-40 \%$ of patients with SCID. ${ }^{1}$ The $\gamma_{c}$ chain is shared by several hematopoietic cytokine receptors, including the interleukin (IL)-2, IL-4, IL-7, IL-9, IL-15, and IL-21 receptors. ${ }^{2}$ Whereas defective IL-7 and IL-15 pathways are responsible for the early block in $\mathrm{T}$ and natural killer (NK) cell differentiation, respectively, abrogation of IL-21 receptor functions is the substrate for humoral dysfunctions. The IL-21 receptor is a major factor in the survival and proliferation of memory/ switched B cells and (in contrast to the IL-4R) cannot be functionally replaced by other receptors. ${ }^{3,4}$ In view of the many physiological roles of $\gamma_{c}$, SCID$\mathrm{X} 1$ is characterized by (1) the absence of circulating $\mathrm{T}$ and NK cells and (2) normal to elevated numbers of poorly functional mature B cells. ${ }^{5}$ Moreover, patients with SCID-X1 treated by allogeneic hematopoietic stem cell transplantation (HSCT) show a high incidence of human papillomavirus (HPV) disease, with a median onset of 8 years

${ }^{*}$ Correspondence:Dr. Marina Cavazzana, Biotherapy Department, Necker Children's Hospital, 149 rue de Sèvres, 75015 Paris, France. E-mail:m.cavazzana@aphp.fr; or Dr. Salima HaceinBey-Abina, Immunology Laboratory, Groupe Hospitalier Universitaire Paris-Sud, AP-HP, 78, rue du Général-Leclerc, 94270 Le-Kremlin-Bicêtre, France. E-mail: salima.hacein-bey@aphp.fr

(C) Marina Cavazzana, et al., 2016; Published by Mary Ann Liebert, Inc. This Open Access article is distributed under the terms of the Creative Commons Attribution Noncommercial License (http://creativecommons.org/licenses/by-nc/4.0/) which permits any noncommercial use, distribution, and reproduction in any medium, provided the original author(s) and the source are credited. 
posttransplantation. The fact that patients with other forms of SCID do not have any signs of HPV disease implies that the lack of a common cytokine receptor $\gamma$ chain or the lack of Janus kinase-3 (JAK-3) are the only genetic factors that predispose to this infection. It also suggests that $\gamma_{\mathrm{c}} / \mathrm{JAK}-$ 3 -dependent signaling in keratinocytes has a role in anti-HPV immunity. ${ }^{6}$

Ever since gene therapy was first envisaged as a treatment for hematopoietic diseases, SCID-X1 has been considered a good model in view of (1) the severity of the disease, (2) the expectation that the restoration of $\gamma_{c}$ expression will confer a selective advantage on the transduced lymphoid progenitors, (3) the long life span of T cells (with the potential for prolonged benefit in treated patients), and (4) the constitutive expression of the $\gamma_{c}$ chain in all hematopoietic lineages (prompting researchers to hope that no adverse effects would be observed, even in the absence of tight regulation of the transgene by its own promoter). In fact, the $\gamma_{c}$ chain forms a part of complex dimeric or trimeric receptors, and its function is controlled by the other subunits.

Moreover, the strong selective advantage expected in the context of this primary immunodeficiency is also based on the availability of $\mathrm{T}$ cell niches within the thymus (due to the absence of pro-T cell precursors). All these expectations have been confirmed by the results of gene therapy trials in SCID-Xl.

\section{PRECLINICAL EXPERIMENTS}

Gammaretroviral vectors with long terminal repeat (LTR)-driven transgene expression were initially chosen for the stable integration of a functional copy of $\gamma_{\mathrm{c}}$ into the genome of $\mathrm{CD}^{+} 4^{+}$hematopoietic stem/progenitor cells (HSPCs). There were several reasons behind this choice:

1. Gammaretroviruses were the first retroviruses to be fully sequenced (in the second half of the 1990s). ${ }^{7}$

2. Their sequencing facilitated the establishment of stable packaging cell lines for the production of defective retroviral vectors (i.e., free of replication-competent retroviruses, which were considered at that time to represent the main risk of insertional mutagenesis). ${ }^{8}$

3. The integration pattern was expected to be random, and thus gammaretroviruses were expected to target primarily noncoding regions of the genome.

A second step toward the first clinical trial of SCID-X1 gene therapy resulted from better fundamental knowledge of the factors that drive the survival and proliferation of HSPCs. The cloning of FLT-3 ligand (FLT-3L) and thrombopoietin significantly facilitated the use of the cytokine cocktails (which also included IL-3 and stem cell factor [SCF]) that improve the induction of $\mathrm{CD} 34^{+}$cell division and boost HSPC survival. ${ }^{9,10}$ When combined with the fibronectin fragment RetroNectin, the use of these cytokines raised the transduction efficiency with human CD $34^{+}$cells from $1-3 \%$ to as much as $30 \%$ - prompting us to thinking that it was time to move into the clinic. ${ }^{11,12}$

Extensive in vitro experiments and in vivo complementation experiments in $\gamma_{c}$ knockout mice enabled us to assemble the preclinical data required for submission of the first clinical trial protocol (which was approved in January 1999). ${ }^{13-16}$

\section{CLINICAL RESULTS}

Table 1 summarizes the results of the various clinical trials. The first clinical trial of gene therapy for SCID-X1 was performed at Necker Children's Hospital (Paris, France) between 1999 and 2002. It was based on a conventional, amphotropic, murine leukemia virus (MLV)-based vector in which $\gamma_{c}$ gene expression was driven by the LTR. ${ }^{17-19}$ Ten children under the age of 1 year were enrolled; all lacked an HLA-identical sibling. This trial was followed by a similar one with a gibbon-ape leukemia virus (GALV)-pseudotyped retrovirus (also performed on 10 patients) at Great Ormond Street Hospital (London, UK). ${ }^{20,21}$ Both trials omitted preconditioning of the patients before gene therapy.

When considering the total of 20 patients enrolled in the two trials, 17 had a stably corrected immunological phenotype. ${ }^{17-21}$ The time course and robustness of $\mathrm{T}$ lymphocyte reconstitution were reproducible (regardless of a patient's age and clinical status) but were directly related to the number of infused CD34 $4^{+} \gamma_{\mathrm{c}}{ }^{+}$cells. In some patients, circulating $\mathrm{CD}^{+} \mathrm{TCR} \alpha \beta^{+}$could be detected (between 10 and $100 / \mu \mathrm{l}$ ) as early as 1 month after the injection of transduced autologous CD34 ${ }^{+}$cells. Normal counts were achieved between 3 and 6 months posttherapy and remained stable over time for all patients (except those who developed monoclonal lymphoproliferative disease; see below). Circulating T cells expressed surface $\gamma_{c}$ to the same extent as (or a slightly lower extent) than control T cells. Functional characteristics of the $\mathrm{T}$ cell population were also satisfactory. The cells proliferated in vitro in response to mitogens and vaccine antigens, and provided effective protection against infection in vivo (as evidenced by recovery from infections during the first few months after gene therapy). ${ }^{19,20}$ 
Table 1. Summary of $X$-Linked severe combined immunodeficiency gene therapy trials

\begin{tabular}{|c|c|c|c|c|c|c|c|c|}
\hline Vector & Centers & Pseudotyping & Conditioning & Inclusion criteria & Patients (n) & Results & SAES & $\operatorname{Ref}(s)$ \\
\hline Gammaretro & France & Ampho & No & & 10 & $\begin{array}{l}\text { Stably corrected immune } \\
\text { function (T cells) }\end{array}$ & 4 T-ALL & $17,19,22$ \\
\hline Gammaretro & UK & GALV & No & & 10 & $\begin{array}{l}\text { Stably corrected immune } \\
\text { function (T cells) }\end{array}$ & $1 \mathrm{~T}-\mathrm{ALL}$ & $20,21,24$ \\
\hline Gammaretro & USA & GALV & No & Patients $>10 \mathrm{yr}$ old, post-HSCT & 3 & Partial clinical benefit & None & 28 \\
\hline SIN-gammaretro & UK, USA & GALV & No & $\begin{array}{l}\text { No HLA-genoidentical donors } \\
\text { Severe, ongoing, treatment- } \\
\text { refractory infections } \\
\text { No HLA-genoidentical donors }\end{array}$ & 9 & $\begin{array}{l}\text { Stably corrected immune } \\
\text { function (T cells) }\end{array}$ & None & 27 \\
\hline SIN-lenti & USA & VSVg & $\begin{array}{l}\text { Nonmyeloablative } \\
\text { busulfan }\end{array}$ & $\begin{array}{l}\text { Patients }>2 \text { yr old, } \\
\text { No HLA-genoidentical donors, } \\
\text { mostly post-HSCT }\end{array}$ & 5 & $\begin{array}{l}\text { Early immune recovery } \\
\text { (T, B, and NK } \\
\text { cell correction) }\end{array}$ & None & 31 \\
\hline
\end{tabular}

ampho, amphotropic; GALV, gibbon-ape leukemia virus; HLA, human leukocyte antigen; HSCT, hematopoietic stem cell transplantation; lenti, lentivirus; retro, retrovirus; NK, natural killer; SAEs, serious adverse events; SIN, self-inactivated; T-ALL, T-cell acute lymphocytic leukemia; VSVg, vesicular stomatitis virus G glycoprotein.

A spectratype analysis revealed a fully diversified TCR- $\mathrm{V}_{\beta}$ and TCR-V $\mathrm{V}_{\alpha}$ repertoire. Remarkably, 13 years after treatment, thymopoiesis is still ongoing in most patients (including those who developed leukemia and subsequently received chemotherapy), as evidenced by the stable detection of TCR excision circles in naive T cells.

In contrast to the reconstitution of the $\mathrm{T}$ cell lineage, reconstitution of $\mathrm{NK}$ cells was much weaker; 1 year after gene therapy, the NK cell counts had barely reached $10 \%$ of the control value (as is also observed in an allogeneic HSCT setting). This might have been due to weaker proliferative and/or survival capacities of the NK cell progenitors, relative to those of T cell progenitors. The patients' humoral functions have been partially restored, despite the continuing absence or undetectable level of transduced B cells. ${ }^{19}$ Accordingly, some of the patients no longer require immunoglobulin replacement therapy (five of eight patients in the Paris trial). ${ }^{19}$ However, virtually all of the patients show a defect in the memory B cell subpopulation and thus in the production of high-affinity antibodies and the response against recall antigens. These results (which are similar to those observed after allogeneic HSCT in the absence of myeloablation) indicate that the development of full humoral responses and the longterm maintenance of normal levels of memory B cells can be achieved only by stable engraftment of genetically modified HSPCs. This requires access to the hematopoietic niches by conditioning the patient before transplantation. ${ }^{19}$

Taken as a whole, these data demonstrate that genetic correction of $\mathrm{T}$ cell immunity restored the patients' general health status and enabled them to lead a normal life with long-lasting beneficial effects (median follow-up, 13 years).

Unfortunately, four patients in the French study and one patient in the U.K. trial developed T cell leukemia 2 to 5.5 years after gene therapy. Four of them remain in long-term remission after chemotherapy ${ }^{22-24}$ and have fully recovered after treatment-thanks to good immunological reconstitution by the residual $\gamma_{c}$-corrected bone marrow CD $34^{+}$cells or thymic progenitors with a high selfrenewal ability. ${ }^{19,20}$ The remaining patient died of chemotherapy-refractory leukemia, despite the deployment of a range of therapeutic approaches (conventional chemotherapy; the generation and administration of a specific monoclonal antibody directed against the $\gamma_{c}$-expressing leukemic clone, complemented with allogeneic transplantation from an unrelated, matched donor). ${ }^{19,22,23}$ In all cases, the adverse event was the result of insertional oncogenesis. Genetic analysis of the malignant cells showed that the retroviral vector had integrated within or near tumor-promoting genes (mainly the LIM domain only-2 gene, LMO2) and had caused transcriptional activation.

To improve the safety profile of gene therapy for SCID-X1 while maintaining the excellent immunologic outcome seen in previous trials, the original vector (MFG- $\left.\gamma_{c}\right)$ was modified to create a selfinactivating (SIN) gammaretrovirus in which (1) the IL2RG cDNA is under the control of the weak, human elongation factor- $1 \alpha$ short promoter, and (2) the strong viral enhancers in the LTRs have been deleted. ${ }^{25,26}$ This vector was used in an international study with participating centers in Paris, London, Boston, Cincinnati, and Los Angeles. In contrast to the first SCID-X1 trials, this trial was restricted to patients with severe, ongoing, treatment-refractory infections (for whom the prognosis after allogeneic HSCT would have been poor). In London and Boston all patients without an allogeneic HLA-identical donor have been treated without further restriction. A preliminary report on the first nine patients enrolled 
since December 2010 was published. ${ }^{27}$ All nine nonconditioned patients (aged between 3.9 and 10.5 months) received bone marrow-derived $\mathrm{CD} 34^{+}$cells transduced with the same GMP-grade SIN gammaretrovirus supernatant. After up to 48 months of follow-up, the overall survival was excellent: eight of the nine patients were alive and well but one had died of an overwhelming adenoviral infection (present on study entry) 4 months after gene therapy (i.e., before full reconstitution by genetically modified $\mathrm{T}$ cells). Of the remaining eight patients, seven displayed full $\mathrm{T}$ cell reconstitution and normalized T cell proliferation. Early immune recovery was as rapid as in the previous trials, but humoral function was not restored in these patients. An insertion site analysis of the patients' peripheral blood mononuclear cells revealed significantly less clustering within proto-oncogenes and genes involved in the serious adverse events (SAEs) in previous gene therapy trials ${ }^{27}$-indicating that this modified SIN gammaretroviral vector is efficacious in the treatment of SCID-X1 and may have a better safety profile.

In addition to these 29 typical patients with SCID$\mathrm{X} 1$ treated a few months after birth, gene therapy was attempted in five older patients with SCID-X1 (aged 10-20 years) as a rescue treatment option after HSCT failure. Three of them were included in the trial conducted at the National Institutes of Health (NIH, Bethesda, MD) in $2003 .{ }^{28}$ No significant clinical benefit was achieved in these subjects; this was likely due to the age-dependent loss of thymic activity and/or a history of graft-versus-host disease (GvHD) and chronic infection. ${ }^{28,29}$

Another clinical trial in SCID-X1 (based on an SIN lentiviral vector expressing the $\gamma_{\mathrm{c}}$ gene) is ongoing at St. Jude Children's Research Hospital (Memphis, TN) and at the NIH; the preliminary results appear to be promising. ${ }^{30,31}$

After more than 16 years of follow-up for the first treated patients with SCID-X1 and more than 5 years for the patients in the second trial, some important conclusions can now be drawn:

1. The robustness of $\mathrm{T}$ cell reconstitution (i.e., required for a protective, stable $\mathrm{T}$ cell count) is directly linked to the number of transduced CD $34^{+} \gamma_{\mathrm{c}}{ }^{+}$cells infused into the patient.

2. Patients with SCID-X1 massively infected with opportunistic pathogens run a high risk of dying soon after transplantation-even in the context of a successful gene-modified autologous transplantation. In this setting, methods for further accelerating $\mathrm{T}$ cell generation are needed (see below).
3. In the absence of myeloablation, ongoing normal $\mathrm{B}$ cell differentiation constitutes an obstacle to efficient recovery of humoral immunity.

4. A gene therapy approach is more likely to succeed in patients less than 1 year of age, because older patients present with thymus damage as a result of a long history of infections (and/or GvHD in those having first undergone HSCT).

With a view to gathering further evidence on the efficacy of immune reconstitution, we compared the results of gene therapy with those of conventional treatment (i.e., haploidentical allogeneic HSCT). Besides the higher rate of severe complications observed in patients who underwent haploidentical HSCT, the results for naive $\mathrm{T}$ cell and total $\mathrm{CD}^{+}$cell counts up to 5 years posttherapy ${ }^{32}$ argue in favor of gene therapy. The results emphasized the importance of continuous, clinical evaluation of the different approaches in terms of mortality and long-term morbidity when studying monogenic diseases of the lymphohematopoietic system.

\section{TOWARD A COMPREHENSIVE INTEGROME ANALYSIS AND GREATER SAFETY}

The development of leukemic SAEs after gene therapy has deeply challenged our understanding of gammaretroviral vector integration and has revealed the acute need for animal models that can predict the genotoxicity of integrating viral vectors. We and others have striven to use various strains of transgenic or knockout mice as animal models that reproduce the clinical observations. Montini and colleagues described a $\mathrm{CDKN}^{-/-}$ model to test for toxicity specifically linked to various vectors. ${ }^{33}$ In 2006, Shou and colleagues bred a $\gamma_{\mathrm{c}}{ }^{-/-}$mouse into a p19Arf ${ }^{-1-}$ background and performed gammaretroviral gene therapy experiments for the correction of $\gamma_{c}{ }^{-/-}$deficiency. ${ }^{34}$ The additional knockout of the tumor suppressor p19Arf revealed minor oncogenic effects in the course of gammaretroviral gene therapy. It could be shown that in the $\mathrm{Arf}^{-1-} \gamma_{\mathrm{c}}{ }^{-1-}$ model, the $\gamma_{\mathrm{c}}{ }^{-1-}$ background of the donor cells and the transgene $\gamma_{c}$ (but not the vector integration itself) have roles in leukemogenesis after retroviral gene therapy. However, these observations have yet to be confirmed. Our laboratory has developed two different models (an LMO2 transgenic mouse and an $\mathrm{Arf}^{-{ }^{-}} \mathrm{Rag} 1^{-/}$tumor-prone gene therapy model) with a view to mimicking clinical observations (J. Hauer, unpublished data). 
Neither of the two models could reproduce the SAEs observed in patients. In parallel, a number of other studies of animal models have yielded contradictory results $^{35-37}$-emphasizing that these models are unable to predict toxic events in clinical trials.

Another approach for tracking insertional mutagenesis is the in vitro immortalization assay developed by Baum's group. For example, the assay can reveal clonal imbalance driven by $M D S 1$ and EVI1 complex locus protein (MECOM) ${ }^{38,39}$ However, this cell culture assay might not be suitable for detecting all mutagenesis events-especially in the lymphoid lineage. Other assays have also been developed for analyzing more specifically the transcriptional activation of $\mathrm{LMO} 2 .^{40,41}$

Despite major progress in vector safety, the absence of a perfectly reliable in vivo or in vitro model for predicting SAEs means that we shall continue to adopt a cautious approach in all future clinical trials. It will certainly be essential to combine several different preclinical strategies (such as xenotransplantation and high-throughput integration site analysis) in order to ensure safety. ${ }^{42}$ In this context, the in-depth monitoring of retroviral integration site (RIS) patterns will help us to develop safer clinical trials.

Significant efforts have gone into the optimization of RIS analysis. The goal has been to enable better coverage and to increase sensitivity by using techniques such as ligation-mediated PCR $(\mathrm{LM}-\mathrm{PCR})^{43}$ and linear amplification-mediated PCR (LAM-PCR). ${ }^{44}$ Several drawbacks (such as the requirement for restriction enzymes) have been successfully circumvented by using more random DNA fragmentation with a combination of enzymes, acoustic shearing, ${ }^{45}$ or nonrestrictive LAMPCR (which works on circular DNA). ${ }^{46}$ Much effort has also gone into the precise analysis of these databases, in order to accurately map RIS positions in the genome. ${ }^{47,48}$ Last, in the case of random shearing, integration sites can be quantified precisely through the enumeration of the various shear fragments containing a given integration site (in contrast to read counts, which can be biased by PCR amplification steps). ${ }^{49}$

Studies of gammaretroviral vector integration in the human genome indicate that this process is not random; each type of retrovirus follows a unique set of precise rules, which explains the biased pattern of integration sites in transduced human cells. The Moloney MLV-derived vectors preferentially integrate into transcriptionally active promoters and regulatory regions, with a symmetrical accumulation around the transcription start site. Moreover, the integrations characteristically ac- cumulate around enhancer and promoter regions; this is associated with modifications of histones H3K4me3 and H3K9me1, which are involved in chromatin configuration and binding to RNA polymerase II. ${ }^{50}$ Transcriptional enhancers present in the MLV LTR were responsible for the activation of the proto-oncogene; they caused not only $\mathrm{T}$ cell acute lymphoblastic leukemia in the first two clinical trials for SCID-X $1^{22-24}$ and in another gene therapy trial for Wiskott-Aldrich syndrome (WAS ${ }^{51}$ but also myelodysplastic syndrome in patients treated for chronic granulomatous disease. $^{52,53}$ This drawback led to the development of two distinct strategies.

The first was based on modified SIN retroviral vectors in which the enhancer regulatory sequences had been replaced by internal promoters capable of inducing limited (and, in some cases, tissue-specific) transcription of the therapeutic gene. ${ }^{25,26}$ In a trial using the SIN gammaretroviral vector, pyrosequencing enabled us to increase the retrieval of RISs by a factor of more than 50 (30,000 sites for the 9 patients treated in this trial, ${ }^{27}$ relative to the 572 identified in the early MLV $\gamma_{c}$ trials $^{54}$ ). Although the RIS distribution and diversity were similar in the two settings, we found that 19 RIS clusters detected in the first full MLV SCID-X1 trial were significantly less common in the second trial. Interestingly, the greatest reduction in the number of integrations was seen for the MECOM, CCND2, and LMO2 clusters, suggesting that integration near these genes and gene activation mediated by the native LTR enhancer had favored clonal expansion. The significant reduction in these clusters suggests that SIN vectors are safer, as also confirmed by the absence of SAEs in the latest results from the corresponding clinical trials.

The second way to increase the safety of gene transfer vectors is based on HIV-derived vectors. This option constitutes a further step toward the prevention of insertional mutagenesis, because the integration profile of the HIV-derived vectors shows that they (1) do not target regulatory elements of the genome and (2) are randomly distributed across actively transcribed genes, with no preference for "dangerous" oncogenes. ${ }^{55,56}$

Nevertheless, two papers show that lentiviral vector integration is responsible for an aberrantly spliced, chimeric transcript ${ }^{57}$ and that lentiviral vectors integrate into a small chromosomal zone near the nuclear pores ${ }^{58}$ which further reduces the randomness of integration. It is impossible to say whether these discoveries may have clinical consequences. Integration profile studies in patients with HIV have also been highly informative, 
showing the presence of clonally expanded T cells with integration in cancer genes such as MLK2 or $B A C H{ }^{59,60}$ However, the positional effect of these integrations has been challenged by the demonstration that these expanded clones contain defective viruses and were more frequently associated with intergenic regions and lower gene expression levels. ${ }^{61}$

The tracking of integration site patterns in different settings will continue to be highly informative. The full integrome is becoming even more accessible by the new high-throughput sequencing approaches, and ongoing developments should enable rapid access to a comprehensive integration repertoire via specific capture approaches and direct genome sequencing.

We and others have shown that it is now possible to map approximately 10,000 RISs per patient in the new lentivirus-based gene therapy trials (for WAS and metachromatic leukodystrophy). ${ }^{62-64}$ The follow-up of these RISs will be critical in terms of both safety and basic science, because it constitutes a unique opportunity to better understand the dynamics of hematopoietic progenitors.

Many barcoding studies in the mouse and in the macaque have tracked various myeloid and lymphoid cell types over time and thus have generated a more precise map of the hematopoietic hierarchy. ${ }^{65-69}$ Similar work in humans can now be performed by efficient RIS analysis, as illustrated in a study highlighting the long-term survival of $\mathrm{T}$ memory stem cells. ${ }^{70}$ The long-term follow-up of the dynamics of naive and memory $\mathrm{T}$ cell populations in the SCIDX1 trials will also enable us to better understand human thymopoiesis and immune responses. Overall, the clonal tracking of RISs in human gene therapy trials will pave the way to a deeper understanding of human hematopoiesis.

\section{SOME BIOLOGICAL AND CLINICAL COM- MENTS, AND EXPECTED IMPROVEMENTS}

Self-inactivating vectors have formally demonstrated their improved safety profile (relative to LTR-driven retroviral vectors), as no SAEs have been observed since their first use in clinical trials in 2006. ${ }^{71}$ Another dogma has been also deeply challenged by the last 20 years of RIS analysis: changes due to the clonal dominance of a single integration site. ${ }^{72}$ Indeed, the thalassemia patient initially showing a dominant clone in the HMGA2 locus is still free of any complication 8 years after gene therapy $^{73}$ (M. Cavazzana and S. Hacein-Bey-Abina, unpublished observations). Interestingly, the abundance of this clone progressively decreased during the follow-up period. A similar observation was made in one of our patients with SCID-X1 treated in the second trial based on the SIN gammaretroviral vector. The patient displayed a dominant clone that varied over time-albeit without any clinical impact. ${ }^{72}$ Furthermore, a growth advantage leading to clonal dominance has been observed in the absence of further transformation toward malignant clones. ${ }^{74}$ Moreover, these observations are in line with arrayed lentiviral barcoding studies in the mouse, which showed that steady-state hematopoiesis can be maintained by a small number of relatively dominant clones. ${ }^{75}$ Clonal hematopoiesis has also been documented in healthy individuals over the age of 65 years, due to somatic mutations, suggesting that clonal dominance is possible in the absence of integration site effects. ${ }^{76}$

Given (1) the current inability to predict adverse events (despite intense work on RIS analysis) and (2) the absence of an accurate animal or in vitro model of toxicity, the continuous clinical follow-up of the patients is the only way to monitor the safety and efficacy of new vector designs and other technical improvements. Last, our ability to further increase the vector copy number per cell raises the question of how many vector copies can be "tolerated" without perturbing normal transcription. The development of "safe harbor" integration would obviate the risk of transactivation after integration.

Another major, unresolved concern is the time needed to generate functional $\mathrm{T}$ cells that can successfully fight the systemic, opportunistic viral infections responsible for poor outcomes in some patients treated by gene therapy. ${ }^{27-29}$

One potential strategy (being developed by our laboratory) involves the infusion of $\mathrm{T}$ cell precursors able to seed the thymus and differentiate into mature $\mathrm{T}$ cells more rapidly than uncommitted CD34 ${ }^{+}$cells. To this end, we have developed an in vitro feeder cell-free culture system based on the use of a recombinant, modified DL-4 ligand that allows the generation of large numbers of CD34 ${ }^{+/-} \mathrm{CD}^{+} \mathrm{T}$ cell precursors within 3-7 days. These precursors resemble their thymic in vivo counterparts in terms of the in vitro potential and expression profile. Once injected into NOD/SCID $/ \gamma_{c}$ knockout mice, $\mathrm{T}$ cell precursors generated in this system were able to colonize the thymus and generate a diversified, functional T cell compartment. ${ }^{77}$ In preliminary experiments, the combination of DL-4 culture and transduction of a SCID-X1 patient's $\mathrm{CD} 4^{+}$cells enabled the production of gene-corrected $\mathrm{T}$ cell precursors. The latter rapidly generated a wave of mature $\mathrm{T}$ cells in vitro and 
then in vivo in $\mathrm{NOD} / \mathrm{SCID} / \gamma_{\mathrm{c}}$ knockout micesuggesting that this strategy shortens $\mathrm{T}$ cell reconstitution, relative to uncultured $\mathrm{CD} 34^{+}$counterparts.

Because gene therapy has proved its effectiveness in several hereditary diseases of the hematopoietic system, the next major milestone will be the long-term safety of the new vectors under investigation. Another challenge is to develop a process that can be disseminated worldwide, that is, to regions of the world where some of the hereditary diseases that might be approached by gene therapy are more prevalent.

Since the first clinical trial in which we defined the whole gene therapy procedure ${ }^{78}$ a number of small and nonsignificant changes have been introduced into the transduction process. Hundreds of papers have been published on various cytokine cocktails, reagents, and drugs expected to make $\mathrm{CD} 4^{+}$cells cycle without losing their self-renewal capacity. A technical breakthrough has been described by Verhoeyen's group. They demonstrated that a baboon envelope pseudotyped lentiviral vector transduces more than $90 \%$ of $\mathrm{CD}^{+} 4^{+}$cells in 24 hours in the presence of low cytokine concentrations. ${ }^{79}$ The impact of ex vivo cell culture and stimulation itself also appear to be difficult to measure. In light of the most recent publications, it would be useful to have a culture procedure that did not require active stimulation of human HSPCs.

Automation of the procedure would also constitute progress, so that any transplantation unit in the world would be able to perform gene correction on autografts independently.

The development of an industrial process would be a further step toward the generalization of gene therapy for the many patients with hereditary diseases of the hematopoietic system. It would also pave the way to gene therapy for diseases outside the hematopoietic system.

\section{ACKNOWLEDGMENTS}

This work was supported by grants from the European Union Seventh Framework Program for Research (CELL-PID 261387), the Programme Hospitalier de Recherche Clinique of the Health Ministry, the Assistance Publique-Hôpitaux de Paris (PHRC national 2008 00-64), the European Research Council (ERC Regenerative Therapy 269037), the French Muscular Dystrophy Association (AFM), and the French National Research Agency under the "Investments for the Future" program (ANR-01-A0-IAHU). The authors thank the patients' families for their continuous support of the study; the medical and nursing staff of the Immunology and Pediatric Hematology Department, Necker's Hospital, for patient care; and the staff of the Biotherapy Department, Necker's Hospital, for their work and support.

\section{AUTHOR DISCLOSURE}

There are no conflicts of interest.

\section{REFERENCES}

1. Noguchi $M, Y_{i} H$, Rosenblatt $H M$, et al. Interleukin-2 receptor $\gamma$ chain mutation results in X-linked severe combined immunodeficiency in humans. Cell 1993;73:147-157.

2. Sugamura K, Asao $H$, Kondo $M$, et al. The interleukin-2 receptor $\gamma$ chain: its role in the multiple cytokine receptor complexes and T cell development in XSCID. Annu Rev Immunol 1996;14:179-205.

3. Leonard WJ. The molecular basis of X-linked severe combined immunodeficiency: defective cytokine receptor signaling. Annu Rev Med 1996; 47:229-239.

4. Avery DT, Deenick EK, Ma CS, et al. B cell-intrinsic signaling through IL-21 receptor and STAT3 is required for establishing long-lived antibody responses in humans. J Exp Med 2010;207:155-171.

5. Buckley RH. Primary immunodeficiency diseases: dissectors of the immune system. Immunol Rev 2002;185:206-219.

6. Laffort C, Le Deist F, Favre M, et al. Severe cutaneous papillomavirus disease after haemo- poietic stem-cell transplantation in patients with severe combined immune deficiency caused by common $\gamma_{c}$ cytokine receptor subunit or JAK-3 deficiency. Lancet 2004;363:2051-2054.

7. Cavazzana-Calvo M, and Gisselbrecht S. Mutagenèse insertionnelle et thérapie génique [Insertional mutagenesis and gene therapy] [article in French]. Hématologie 2005;11:173-180.

8. Mulligan RC. Development of gene transfer technology. Hum Gene Ther 2014;25:995-1002.

9. Dao MA, Hannum CH, Kohn DB, et al. FLT3 ligand preserves the ability of human $\mathrm{CD}_{3} 4^{+}$progenitors to sustain long-term hematopoiesis in immunedeficient mice after ex vivo retroviral-mediated transduction. Blood 1997;89:446-456.

10. Petzer AL, Zandstra PW, Piret JM, et al. Differential cytokine effects on primitive $\left(\mathrm{CD}_{3} 4^{+} \mathrm{CD} 38^{-}\right)$human hematopoietic cells: novel responses to Flt3-ligand and thrombopoietin. J Exp Med 1996;183:2551-2558.

11. Hanenberg H, Xiao XL, Dilloo D, et al. Colocalization of retrovirus and target cells on specific fibronectin fragments increases genetic transduction of mammalian cells. Nat Med 1996;2:876-882.

12. Kiem HP, Andrews RG, Morris J, et al. Improved gene transfer into baboon marrow repopulating cells using recombinant human fibronectin fragment $\mathrm{CH}-296$ in combination with interleukin-6, stem cell factor, FLT-3 ligand, and megakaryocyte growth and development factor. Blood 1998;92: 1878-1886.

13. Hacein-Bey H, Cavazzana-Calvo M, Le Deist $F$, et al. $\gamma_{c}$ gene transfer into SCID X1 patients' Bcell lines restores normal high-affinity interleukin2 receptor expression and function. Blood 1996; 87:3108-3116.

14. Cavazzana-Calvo M, Hacein-Bey S, de Saint Basile G, et al. Role of interleukin-2 (IL-2), IL-7, and IL-15 in natural killer cell differentiation from cord blood hematopoietic progenitor cells and from $\gamma_{c}$ transduced severe combined immunodeficiency $\mathrm{X} 1$ bone marrow cells. Blood 1996;88:3901-3909.

15. Hacein-Bey S, Basile GD, Lemerle J, et al. $\gamma_{c}$ gene transfer in the presence of stem cell factor, FLT- 
3L, interleukin-7 (IL-7), IL-1, and IL-15 cytokines restores T-cell differentiation from $\gamma_{c}{ }^{-}$X-linked severe combined immunodeficiency hematopoietic progenitor cells in murine fetal thymic organ cultures. Blood 1998;92:4090-4097.

16. Soudais C, Shiho T, Sharara LI, et al. Stable and functional lymphoid reconstitution of common cytokine receptor $\gamma$ chain deficient mice by retroviralmediated gene transfer. Blood 2000;95:3071-3077.

17. Cavazzana-Calvo M, Hacein-Bey S, de Saint Basile $\mathrm{G}$, et al. Gene therapy of human severe combined immunodeficiency (SCID)-X1 disease. Science 2000;288:669-672.

18. Hacein-Bey-Abina S, Le Deist F, Carlier F, et al. Sustained correction of $X$-linked severe combined immunodeficiency by ex vivo gene therapy. N Engl J Med 2002;346:1185-1193.

19. Hacein-Bey-Abina S, Hauer J, Lim A, et al. Efficacy of gene therapy for X-linked severe combined immunodeficiency. N Engl J Med 2010;363:355-364.

20. Gaspar HB, Cooray S, Gilmour KC, et al. Longterm persistence of a polyclonal $T$ cell repertoire after gene therapy for $\mathrm{X}$-linked severe combined immunodeficiency. Sci Transl Med 2011;3:97ra79.

21. Gaspar HB, Parsley KL, Howe S, et al. Gene therapy of $X$-linked severe combined immunodeficiency by use of a pseudotyped gammaretroviral vector. Lancet 2004;364:2181-2187.

22. Hacein-Bey-Abina $S$, Garrigue A, Wang GP, et al. Insertional oncogenesis in 4 patients after retrovirus-mediated gene therapy of SCID-X1. J Clin Invest 2008;118:3132-3142.

23. Hacein-Bey-Abina S, Von Kalle C, Schmidt M, et al. LMO2-associated clonal T cell proliferation in two patients after gene therapy for SCID-X1. Science 2003;302:415-419.

24. Howe SJ, Mansour MR, Schwarzwaelder K, et al. Insertional mutagenesis combined with acquired somatic mutations causes leukemogenesis following gene therapy of SCID-X1 patients. J Clin Invest 2008;118:3143-3150.

25. Thornhill SI, Schambach A, Howe SJ, et al. Selfinactivating gammaretroviral vectors for gene therapy of $X$-linked severe combined immunodeficiency. Mol Ther 2008;16:590-598.

26. Zychlinski D, Schambach A, Modlich U, et al. Physiological promoters reduce the genotoxic risk of integrating gene vectors. Mol Ther 2008;16: 718-725.

27. Hacein-Bey-Abina S, Pai S-Y, Gaspar HB, et al. A modified $\gamma$-retrovirus vector for $X$-linked severe combined immunodeficiency. N Engl J Med 2014; 371:1407-1417.

28. Chinen J, Davis J, De Ravin SS, et al. Gene therapy improves immune function in preadolescents with X-linked severe combined immunodeficiency. Blood 2007;110:67-73.

29. Thrasher AJ, Hacein-Bey-Abina S, Gaspar HB, et al. Failure of SCID-X1 gene therapy in older patients. Blood 2005;105:4255-4257.
30. De Ravin SS, Gray JT, Throm RE, et al. Falsepositive HIV PCR test following ex vivo lentiviral gene transfer treatment of $\mathrm{X}$-linked severe combined immunodeficiency vector. Mol Ther 2014; 22:244-245

31. De Ravin SS, Wu X, Theobald N, et al. Lentiviral hematopoietic stem cell gene therapy for older patients with X-linked severe combined immunodeficiency. Blood 2015;126:261-261.

32. Touzot F, Moshous D, Creidy R, et al. Faster T-cell development following gene therapy compared to haplo-identical hematopoietic stem cell transplantation in the treatment of SCID-X1. Blood 2015;125:3563-3569.

33. Montini E, Cesana D, Schmidt M, et al. The genotoxic potential of retroviral vectors is strongly modulated by vector design and integration site selection in a mouse model of HSC gene therapy. J Clin Invest 2009;119:964-975.

34. Shou Y, Ma Z, Lu T, et al. Unique risk factors for insertional mutagenesis in a mouse model of XSCID gene therapy. Proc Natl Acad Sci U S A 2006:103:11730-11735.

35. Scobie L, Hector RD, Grant L, et al. A novel model of SCID-X1 reconstitution reveals predisposition to retrovirus-induced lymphoma but no evidence of $\gamma C$ gene oncogenicity. Mol Ther 2009;17: 1031-1038.

36. Ginn SL, Liao SH, Dane AP, et al. Lymphomagenesis in SCID-X1 mice following lentivirusmediated phenotype correction independent of insertional mutagenesis and $\gamma_{c}$ overexpression. Mol Ther 2010;18:965-976.

37. Dave UP, Akagi K, Tripathi R, et al. Murine leukemias with retroviral insertions at $L m o 2$ are predictive of the leukemias induced in SCID-X1 patients following retroviral gene therapy. PLoS Genet 2009;5:e1000491.

38. Modlich U, Navarro S, Zychlinski D, et al. Insertional transformation of hematopoietic cells by self-inactivating lentiviral and gammaretroviral vectors. Mol Ther 2009;17:1919-1928.

39. Baum C, Modlich U, Göhring G, et al. Concise review: managing genotoxicity in the therapeutic modification of stem cells. Stem Cells 2011;29: 1479-1484.

40. Ryu BY, Evans-Galea MV, Gray JT, et al. An experimental system for the evaluation of retroviral vector design to diminish the risk for protooncogene activation. Blood 2008;111:1866-1875.

41. Zhou S, Mody D, DeRavin SS, et al. A selfinactivating lentiviral vector for SCID-X1 gene therapy that does not activate LMO2 expression in human T cells. Blood 2010;116:900-908.

42. Stein S, Scholz S, Schwäble J, et al. From bench to bedside: preclinical evaluation of a selfinactivating gammaretroviral vector for the gene therapy of X-linked chronic granulomatous disease. Hum Gene Ther Clin Dev 2013;24:86-98.

43. Wang GP, Ciuffi A, Leipzig J, et al. HIV integration site selection: analysis by massively parallel pyr- osequencing reveals association with epigenetic modifications. Genome Res 2007;17:1186-1194.

44. Schmidt M, Schwarzwaelder K, Bartholomae C, et al. High-resolution insertion-site analysis by linear amplification-mediated PCR (LAM-PCR). Nat Methods 2007:4:1051-1057.

45. Gillet NA, Malani N, Melamed A, et al. The host genomic environment of the provirus determines the abundance of HTLV-1-infected T-cell clones. Blood 2011;117:3113-3122.

46. Gabriel R, Eckenberg R, Paruzynski A, et al. Comprehensive genomic access to vector integration in clinical gene therapy. Nat Med 2009;15: 1431-1436.

47. Arens A, Appelt J-U, Bartholomae CC, et al. Bioinformatic clonality analysis of next-generation sequencing-derived viral vector integration sites. Hum Gene Ther Methods 2012;23:111-118.

48. Calabria A, Leo S, Benedicenti F, et al. VISPA: a computational pipeline for the identification and analysis of genomic vector integration sites. Genome Med 2014;6:67.

49. Berry CC, Gillet NA, Melamed A, et al. Estimating abundances of retroviral insertion sites from DNA fragment length data. Bioinformatics 2012;28: 755-762.

50. Wang GP, Berry CC, Malani N, et al. Dynamics of gene-modified progenitor cells analyzed by tracking retroviral integration sites in a human SCID-X1 gene therapy trial. Blood 2010;115:4356-4366.

51. Braun CJ, Boztug K, Paruzynski A, et al. Gene therapy for Wiskott-Aldrich syndrome-long-term efficacy and genotoxicity. Sci Transl Med 2014;6: 227ra233.

52. Stein S, Ott MG, Schultze-Strasser $S$, et al. Genomic instability and myelodysplasia with monosomy 7 consequent to EVI1 activation after gene therapy for chronic granulomatous disease. Nat Med 2010;16:198-204.

53. Avedillo Diez I, Zychlinski D, Coci EG, et al. Development of novel efficient SIN vectors with improved safety features for Wiskott-Aldrich syndrome stem cell based gene therapy. Mol Pharm 2011;8:1525-1537.

54. Deichmann A, Hacein-Bey-Abina S, Schmidt $M$, et al. Vector integration is nonrandom and clustered and influences the fate of lymphopoiesis in SCID-X1 gene therapy. J Clin Invest 2007;117: 2225-2232.

55. Biffi A, Bartolomae CC, Cesana D, et al. Lentiviral vector common integration sites in preclinical models and a clinical trial reflect a benign integration bias and not oncogenic selection. Blood 2011;117:5332-5339.

56. Moiani A, Miccio A, Rizzi E, et al. Deletion of the LTR enhancer/promoter has no impact on the integration profile of MLV vectors in human hematopoietic progenitors. PLoS One 2013;8:e55721.

57. Moiani A, Paleari $Y$, Sartori D, et al. Lentiviral vector integration in the human genome induces 
alternative splicing and generates aberrant transcripts. J Clin Invest 2012;122:1653-1666.

58. Marini B, Kertesz-Farkas A, Ali $\mathrm{H}$, et al. Nuclear architecture dictates HIV-1 integration site selection. Nature 2015;521:227-231.

59. Maldarelli F, Wu X, Su L, et al. HIV latency. Specific HIV integration sites are linked to clonal expansion and persistence of infected cells. Science 2014;345:179-183.

60. Wagner TA, McLaughlin S, Garg K, et al. HIV latency: proliferation of cells with HIV integrated into cancer genes contributes to persistent infection. Science 2014;345:570-573.

61. Cohn LB, Silva IT, Oliveira TY, et al. HIV-1 integration landscape during latent and active infection. Cell 2015;160:420-432.

62. Biffi A, Montini E, Lorioli L, et al. Lentiviral hematopoietic stem cell gene therapy benefits metachromatic leukodystrophy. Science 2013;341:1233158.

63. Aiuti A, Biasco L, Scaramuzza S, et al. Lentiviral hematopoietic stem cell gene therapy in patients with Wiskott-Aldrich syndrome. Science 2013;341: 1233151.

64. Hacein-Bey Abina S, Gaspar HB, Blondeau J, et al. Outcomes following gene therapy in patients with severe Wiskott-Aldrich syndrome. JAMA 2015; 313:1550-1563.

65. Dykstra B, Kent D, Bowie M, et al. Long-term propagation of distinct hematopoietic differentiation programs in vivo. Cell Stem Cell 2007;1:218-229.
66. Perié L, Hodgkin PD, Naik SH, et al. Determining lineage pathways from cellular barcoding experiments. Cell Reports 2014;6:617-624.

67. Verovskaya E, Broekhuis MJC, Zwart E, et al. Heterogeneity of young and aged murine hematopoietic stem cells revealed by quantitative clonal analysis using cellular barcoding. Blood 2013;122:523-532.

68. Kim S, Kim N, Presson AP, et al. Dynamics of HSPC repopulation in nonhuman primates revealed by a decade-long clonal-tracking study. Cell Stem Cell 2014;14:473-485.

69. Wu C, Li B, Lu R, et al. Clonal tracking of rhesus macaque hematopoiesis highlights a distinct lineage origin for natural killer cells. Cell Stem Cell 2014;14:486-499

70. Biasco L, Scala S, Basso Ricci L, et al. In vivo tracking of $T$ cells in humans unveils decade-long survival and activity of genetically modified T memory stem cells. Sci Transl Med 2015;7:273ra213.

71. Cartier N, Hacein-Bey-Abina S, Bartholomae CC, et al. Hematopoietic stem cell gene therapy with a lentiviral vector in X-linked adrenoleukodystrophy. Science 2009;326:818-823.

72. Cavazzana-Calvo M, Fischer A, Bushman FD, et al. Is normal hematopoiesis maintained solely by long-term multipotent stem cells? Blood 2011;117: 4420-4424.

73. Cavazzana-Calvo $M$, Payen E, Negre 0 , et al Transfusion independence and HMGA2 activation after gene therapy of human $\beta$-thalassaemia. Nature 2010;467:318-322.
74. Fehse B, and Roeder I. Insertional mutagenesis and clonal dominance: biological and statistical considerations. Gene Ther 2008;15:143-153.

75. Grosselin J, Sii-Felice K, Payen E, et al. Arrayed lentiviral barcoding for quantification analysis of hematopoietic dynamics. Stem Cells 2013;31: 2162-2171.

76. Genovese G, Kahler AK, Handsaker RE, et al. Clonal hematopoiesis and blood-cancer risk inferred from blood DNA sequence. N Engl J Med 2014;371:2477-2487.

77. Reimann C, Six E, Dal-Cortivo L, et al. Human T-lymphoid progenitors generated in a feeder-cellfree Delta-like-4 culture system promote T-cell reconstitution in NOD/SCID $/ \gamma c^{--}$mice. Stem Cells 2012;30:1771-1780

78. Hacein-Bey S, Gross F, Nusbaum P, et al. Optimization of retroviral gene transfer protocol to maintain the lymphoid potential of progenitor cells. Hum Gene Ther 2001;12:291-301.

79. Girard-Gagnepain A, Amirache F, Costa C, et al Baboon envelope pseudotyped LVs outperform VSV-G-LVs for gene transfer into early-cytokinestimulated and resting HSCs. Blood 2014;124: 1221-1231.

Received for publication October 7, 2015; accepted after revision January 16, 2016

Published online: January 20, 2016. 